\title{
Manutenção do aleitamento materno no retorno ao trabalho
}

RESUMO | A Pesquisa foi motivada a investigar como as mulheres trabalhadoras realizava a manutenção do aleitamento materno ao retornar de seu trabalho, que teve como objetivo descrever se havia dificuldades e estratégias realizadas para a manutenção do aleitamento. O método análise dos dados pelo referencial de Bardin, realizada entre os meses de setembro à outubro de 2017 , com vinte mulheres entre 19 a 39 anos de idade cadastradas e atendidas na unidade de estratégia saúde da família do município do Rio de Janeiro, sendo produzidas duas categorias: Paradoxo da rede de apoio; Ausência do Enfermeiro no trabalho multiprofissional. Resultado obteve como desmame precoce havendo a introdução de leite pasteurizado como consequência. Conclui-se que há insegurança para a realização de ações de continuidade de aleitamento materno após o retorno ao trabalho.

Palavras-chaves: Aleitamento materno, Mulher trabalhadora, Enfermeiro.

ABSTRACT I The research was motivated to investigate the hard-working women accomplished the maintenance of the maternal breast feeding when returning of his / her work, that he / she had an objective described if there were difficulties and strategies accomplished for the maintenance of the breast feeding. The methodology analysis of the data for the reference of Bardin, conducted between the months of September to October of 2017, twenty women among 19 to 39 years of age registered and assisted in the unit of strategy. municipal district of Rio de Janeiro, being produced two categories: Paradox of the support net; Absence of the Nurse in the multi-professional work. Result obtained how it weans precocious having the introduction of milk pasteurized as consequence. It is ended that there is insecurity for the accomplishment of actions of continuity of maternal breast feeding after the return to the work.

Keywords: Breastfeeding, Working woman, Nurse.

RESUMEN | La investigación fue motivada a investigar cómo las mujeres trabajadoras realizaban el mantenimiento de la lactancia materna al retornar de su trabajo, que tuvo como objetivo describir si había dificultades y estrategias realizadas para el mantenimiento de la lactancia. La metodología análisis de los datos por el referencial de Bardin, realizada entre los meses de septiembre a octubre de 2017, veinte mujeres entre 19 a 39 años de edad registradas y atendidas en la unidad de estrategia salud de la familia del municipio de Río de Janeiro En enero, se producirá dos categorías: Paradoja de la red de apoyo; Ausencia del enfermero en el trabajo multiprofesional. Resultado obtenido como destete precoz habiendo la introducción de leche pasteurizada como consecuencia. Se concluye que hay inseguridad para la realización de acciones de continuidad de lactancia materna después del retorno al trabajo.

Palabras claves: Lactancia materna, Mujer trabajadora, Enfermero.

\section{Fabiana Cabral Arantes Torres}

Bacharel de Enfermagem pela Universidade Castelo Branco (UCB). Residente em saúde da família (PRESF-RJ) Rio de Janeiro, RJ, Brasil.

\section{Fernanda Fatima Pacheco de Oliveira}

Bacharel de Enfermagem pela Universidade Castelo Branco (UCB). Rio de Janeiro, RJ, Brasil.

\section{Claudia Maria Messias}

Doutora em Enfermagem da Escola de Enfermagem Anna Nery (UFRJ). Professora Adjunta da Universidade Federal Fluminense (UFF), Departamento Materno Infantil e Psiquiatria-Niterói, RJ, Brasil.
Maria Regina Bernardo da Silva

Enfermeira Mestra em saúde da família e comunidade UNESA, Professora Enfermeira da Universidade Castelo Branco (UCB). Rio de Janeiro, RJ, Brasil.

\section{Patrícia Salles Damasceno de Matos}

Enfermeira na Maternidade Fernando de Magalhães. Rio de Janeiro, RJ, Brasil.

\section{Ilma Marques Fernandes}

Enfermeira especialista em Saúde da MuIher e obstetrícia social e Mestre em ciências da Enfermagem, ambos pela UERJ. Professora da Universidade Estácio de Sá. Enfermeira de saúde da mulher na Prefeitura de Duque de Caxias. Rio de Janeiro, RJ, Brasil.

Recebido em: 29/11/2018

Aprovado em: 05/06/2019
INTRODUÇÃO

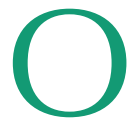

Ministério da Saúde (MS) preconiza a amamentação exclusiva a partir de uma hora após o nascimento até que o bebê tenha 6 meses de idade, os alimentos complementares nutricionais devendo ser adicionados após seis meses de vida e enquanto continuam a amamentar por até 2 anos ou mais, além de proporcionar diversos benefícios à saúde do binômio mãe-filho, família e sociedade ${ }^{1}$.

Vivenciar os desafios da amamentação, acolher e nutrir, obtendo ou não dificuldades no ato, e mesmo com tantos desafios que caem sobre a mulher na tentativa de adequação se deparando com frustrações, dentre elas o longo tempo diário de jornada de trabalho cominando na distância de cuidados com seu filho em um momento onde se é cobrado maior atenção ${ }^{3}$. 
O número de mulheres que afirmam ser o chefe da família aumentou de 29\%, em 2002, para 35\%, em 2012. Ainda de acordo com o IBGE, que elaborou o estudo Estatísticas de Gênero, em 2000, as mulheres chefiavam 24,9\% dos 44,8 milhões de domicílios particulares. Em 2010, 38,7\% dos 57,3 milhões de domicílios registrados já eram comandados por mulheres ${ }^{2}$.

A mulher contemporânea tem dentre seus desafios diários, não só reduzir as diferenças no setor econômico, mas no processo de adequação a esta nova função social e familiar, ao se propor ser mãe e ainda assim trabalhadora, cai sobre ela a responsabilidade de assegurar a qualidade de vida de seu filho mesmo estando horas durante o dia distante de cuidados diretos a ele $\mathrm{e}^{7}$.

Diante deste contexto delineamos como questão norteadora: Quais tem sido as dificuldades e estratégias realizadas pela mulher para a manutenção do aleitamento materno após seu retorno ao trabalho?

\section{MÉTODO}

Trata-se de uma pesquisa empírica, descritiva e exploratória do tipo pesquisa de campo, com abordagem qualitativa4. Onde foram identificadas as estratégias adotadas por vinte mulheres na adaptação ao aleitamento materno após o retorno ao trabalho ${ }^{5}$.

O cenário de pesquisa, foi em uma unidade de Estratégia saúde da família, no município do Rio de Janeiro na Zona Oeste, inserida ao sul da área de Planejamento 5.1, com seu território adscrito alcançando o extremo sul do bairro de Padre Miguel no limite com o bairro de Bangu ${ }^{17}$.

Foram utilizadas vinte muIheres entrevistadas, quatorze foram captadas em consulta de puericultura, e quatro captadas no acolhimento da imunização entre o período de 23 a 26 de outubro de 2017. A inclusão referiu-se somente mulheres-mães trabalha-

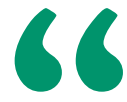

Contudo, a família representa a rede de apoio primária de todo e qualquer indivíduo. É um sistema de relações contínuas e interligadas, estabelecida por meio de uma rede própria de cuidar pautada em valores, crenças e conhecimentos. Desse modo, percebe a rede de apoio como estratégia para ações de incentivo ao aleitamento materno é fundamental para que a mulher possua êxito na realização da amamentação doras formais registradas pela Consolidação das Leis do Trabalho (CLT) e que retornaram ao trabalho antes da criança completar seis meses de vida. Sendo, todas cadastradas na unidade de saúde e maiores de dezoito (18) anos. Sendo excluídas da pesquisa as que não eram mães, as que não tiveram interesse em participar voluntariamente, com a faixa etária menor de 18 anos, que não tinham vínculo empregatício pela CLT, as sem cadastro na Clínica.

Sendo avaliadas e divididas em duas categorias. Com a preservação da identidade das participantes da pesquisa. As seleções iniciais dos temas foram feitas a partir da revisão de literatura, selecionando dados atualizados, relevantes, coerentes e consistentes e que se repetiam em cada análise. Neste estudo os dados foram analisados conforme a técnica de análise de conteúdo de Bardin ${ }^{6}$.

Acrescenta-se que toda a dinâmica desta pesquisa foi regida pelos dispositivos legais que norteiam pesquisas com seres humanos no Brasil, os aspectos éticos, atendeu aos requisitos da Resolução 466/12 do Conselho Nacional de Saúde, relativos à ética na pesquisa com seres humanos, por se tratar de um estudo que envolve seres humanos. Após a liberação do Concelho Nacional de Saúde-Comissão Nacional de Ética em Pesquisa- CONEP com o SMSRJ parecer 2.403.264, com o CAAE 77889317.3.0000.5279

\section{RESULTADOS}

No presente estudo foi verificado que o enfermeiro precisa articular estratégias que visam a integração e humanização durante a consulta de enfermagem, com a evolução de novas técnicas, procedimentos, formulários fatores que influenciam na relação enfermeiro e paciente/usuário ${ }^{12}$, se faz necessário a quebra de "molduras" em torno do aleitamento materno e sua adaptação ao retorno do trabalho, fa- 
zendo da mulher a protagonista desta adaptação esclarecendo duvidas e encontrando alternativas para a manutenção do aleitamento ${ }^{9}$.

\section{DISCUSSÕES}

$1^{\circ}$ Categoria: Paradoxo da rede de apoio.

Destaca-se $30 \%$ de mulheres que declaram manter o aleitamento materno após retorno ao trabalho, tendo como caraterística comum trabalharem próximo a sua residência e contarem com uma rede de apoio.

"Sempre que conseguia um tempo no trabalho na hora do meu almoço eu corria para casa para amamentar...] [..., mas eu tinha ordenhado em casa que minha sogra dava...]" (P3)

Os ganhos a mulher trabalhadora, que mora próximo a sua residência tornam o aleitamento mais efetivo, e menos estressante, adiantando tarefas domésticas ou mesmo cuidados com a criança antes do expediente, além da locomoção do trabalho para casa e de casa ao trabalho em menos tempo ${ }^{19}$.

Contudo, a família representa a rede de apoio primária de todo e qualquer indivíduo. É um sistema de relações contínuas e interligadas, estabelecida por meio de uma rede própria de cuidar pautada em valores, crenças e conhecimentos8. Desse modo, percebe a rede de apoio como estratégia para ações de incentivo ao aleitamento materno é fundamental para que a mulher possua êxito na realização da amamentação ${ }^{11}$.

Embora se reconheça que a rede de apoio exerce papel fundamental no sucesso da amamentação11, na presente pesquisa esta rede aparece de forma paradoxal quando 30\% apontam como uma solução, 55\% atribuem a influência desta como uma das dificuldades de manter o aleitamento e como causa principal o seu retorno ao trabalho, como podemos ver na fala abaixo:
"Por 1 mês do meu retorno do trabalho consegui fazer a retirada do meu leite ...] minha sogra dava na colher... era o que eu achava até que um dia ela comprou uma mamadeira e começou a dá outro leite, sem eu saber, quando eu vi já era tarde...] a pressão da família é grande... pensei em até pedi demissão para cuidar do meu filho...]" (P5)

Evidencia-se que a mulher contemporânea tem dentre seus desafios diários, não só reduzir as diferenças no setor econômico e trabalhista por direitos iguais, mas no processo de adequação a esta nova função social e familiar, ao se propor, ser mãe e ainda assim trabaIhadora, cai sobre ela a responsabilidade de assegurar a qualidade de vida de seu filho, mesmo estando horas durante o dia distante ${ }^{19}$.

Em muitas situações a ordenha de leite materno pode ser necessária, e para manter o aleitamento materno ao retorno ao trabalho, esta técnica é a forma de maior legitimidade e credibilidade, adotada como a primeira prática para a continuidade do aleitamento materno, porém esta técnica deve ser empregada dentro de um processo de confiança e vinculo estabelecido entre a mulher e o profissional de saúde, onde juntos estabeleceram cuidados, esclarecimentos de dúvidas, alcançando assim menos danos possível no processo de adaptação e manutenção do aleitamento materno ${ }^{14}$.

"Meu trabalho atrapalhou muito nisso...eu dava mamadeira tive que deixá-lo na creche. Aí já viu em menos de 1 mês meu filho já estava comendo papinha..." (P11)

Em estudos no cenário brasileiro, traz outras perspectivas, nos últimos 50 anos, as mulheres têm deixado de atuar apenas no ambiente privado para também se lançarem no mercado de trabalho1. Em 2007, as mulheres repre- sentavam 40,8\% do mercado formal de trabalho; em 2016, passaram a ocupar $44 \%$ das vagas. Essa diferença tende a ser reduzida ao longo dos anos ${ }^{2}$.

Diante do exposto, a mulher, possui o conhecimento sobre os benefícios que o aleitamento materno proporciona a criança até os seis meses de vida segundo recomendações da Organização Mundial da Saúde (OMS), e o seu retorno ao trabalho tem sido o responsável principal ao desmame precoce levando em consideração que seu retorno não respeita os seis meses recomendado pala OMS16, tornando o ato de amamentar modificado ao longo do tempo, obedecendo a determinações culturais e socioeconômicas. Retratada pela rede de apoio8, influenciando a mulher no seu período de adaptação ${ }^{15}$.

$2^{\circ}$ Categoria: Ausência do Enfermeiro no trabalho multiprofissional.

O presente estudo destaca que $70 \%$ referencia-se a ação de multiprofissionais de saúde na assistência e orientações quanto ao aleitamento materno e apenas três participantes da pesquisa relatam ter tido a figura do enfermeiro como a principal fonte de orientação na adaptação ao retorno do trabalho, como podemos ver abaixo:

"Nas consultas do pré-natal a enfermeira falava que eu tinha que amamentar, mesmo depois que voltasse para o trabalho mais não me dizia como, agendava para o grupo de gestante..." (P18)

Com a implementação do Programa Saúde da Família (PSF) em todo o Brasil como uma importante estratégia para a reordenação da atenção à saúde, conforme preconizam os princípios e diretrizes do Sistema Único de Saúde ${ }^{18}$. O PSF prioriza as ações de promoção, proteção e recuperação da saúde de indivíduos, famílias e comunidade, de forma integral e continuada, diversos profissionais com a lógica de trabalho multiprofissional, mas é inegável a autonomia 
e representatividade do enfermeiro neste cenário ${ }^{17}$.

"Não tive tanta orientação no pré-natal com o Enfermeiro, procurava tirar dúvidas nos grupos de gestantes com outros profissionais, eles me ensinaram a retira o leite e guardar na geladeira em pote de vidro..." (P13)

Destaca-se a relevância de ações educativas, desenvolvidas pelo trabaIho multiprofissional não apenas com a gestante ou puérpera, mais sua rede de apoio, e o coletivo, tornando-se uma ferramenta útil no PSF, porém o enfermeiro deve estar inserido nas diretrizes da Atenção Básica dentre uma delas está o contexto da longitudinalidade do cuidado proporcionando junto aos demais profissionais a clínica ampliada ${ }^{10}$.

O enfermeiro com sua empatia, é o profissional que mais conhece a mulher, devido à proximidade gerada durante a prestação do cuidado no PSF, a boa qualidade no atendimento de forma planejada e sistemática contribui para a adaptação da mulher que passa por um processo de mudanças decorrentes ao seu retorno ao trabalho e ao aleitamento ${ }^{12}$.

\section{CONCLUSÃO}

Conclui-se que dentre os fatores causadores do desmame precoce, foi verificado a importância do aleitamento materno durante os seis meses essências na vida da criança, além de possuírem conhecimentos do armazenamento e a utilização do leite ordenhado, Entretanto, foi observado que as que não obtiveram sucesso na continuidade do aleitamento exclusivo, ainda assim buscaram outros recursos para que seja mantido o cuidado ao seu filho.

Quanto aos enfermeiros na estratégia saúde da família exercem um papel fundamental nas orientações no período gravídico-puerperal, realizando atividades que garantam o fortalecimento de informações que sejam de fácil compreensão para todas as mulheres, incluindo seus parceiros e seus familiares. Neste sentido, é necessário uma maior sensibilização e entendimento sobre a incorporação de atividades educativas, como método de prevenção e promoção da saúde onde os saberes populares e técnico-cientifico se integre de maneira horizontal.

\section{Referências}

1. Brasil, Ministério da Saúde (MS). Departamento de Atenção Básica. Saúde da Criança, Aleitamento Materno e Alimentação Complementar; Caderno de Atenção Básica n²3. Brasília: ed 2. Ministério de saúde; 2015 Páginas 18, 23, 47, e 48. (MS. Informes técnicos).

2. Garcia H. A mulher no mercado do trabalho, [internet] 2017 [citado 2017 fev 02]; 25(3): 262-69. Disponivel em: http://emporiododireito.com. br/a-mulher-no-mercado-do-trabalho-uma-luta-istorica-que-merece-ser-compartilhada-por-heloise-siqueira-garcia

3. Balogh C. Amamenta, ser mãe além da amamentação, Rio de Janeiro, Posts Mães de peito; [internet] 2016 [citado 2016 abr 04]; 33(3): 185-69. Disponível em: http://www.maesdepeito.com.br/amamentacao/

4. Gil A C. Pesquisa Social. Métodos e Técnicas de Pesquisa Social. São Paulo: Atlas; p. 2010; 5(3) 42- 48.

5. Minayo M C S. (Org). Pesquisa social, Teoria Método e Criatividade. $29^{a}$ Ed. Petrópolis: Vozes; 2010; 5(3): 122-131.

6. Bardin L. Análise de conteúdo (L de A Rego \& amp, A Pinheiro, Trads.). Lisboa: Edições 70; 2011; 9(5): 222-232.

7. Silveira C L, Budó M L D, Silva F M, Durgante V L, Wunsch S, Simon B S. et al. Cuidadora de familiar com a influencia no aleitamento materno: percepções, motivações e repercussões. Rev. Enferm UFSM [Internet]; 2017 [citado 2013 abr 06]; 21(3): 15-18 Disponível em: http://cascavel.ufsm.br/ revistas/ojs2.2.2/index.php/reufsm/article/view/3828

8. Teixeira M A, Nitschke R G, Silva L W S. A prática da amamentação no cotidiano familiar, um contexto intergeracional: influência das mulheres avós. Rev Kairós, [Internet]; 2017 [citado 2014 nov 06]; 21(3): 15-18 Disponível em: http://revistas.pucsp.br/index.php/kairos/article/view/6501 9. Alencar R C V. A vivencia do enfermeiro na ação educativa, no programa saúde da família (PSF), Belo Horizonte - MG, Dissertação de mestrado Universidade Federal de Minas Gerais, p 25, 2013; [Internet]. 2017 [citado 2006 ago 21]; 22(5): 112-120. Disponível em: $9 . \quad \mathrm{http} / / / \mathrm{www}$. scielo.br/pdf/ress/v25n3/2237-9622- ress-25-03-00575.pdf.

10. Mosteschio C, Gaíva M, Moreira M. 0 enfermeiro frente ao desmame precoce na consulta de enfermagem à criança. Rev Bras Enferm. [Internet]; 2017 [citado 2015 Jul 09]; 68(5): 587-93. Disponível em: http://dx. doi.org/10.1590/0034-7167.2015680515i

11. Barreira S M C, Machado M F A S. Amamentação: compreendendo a influência familiar. Acta Sci Health Sci; [Internet]; 2017 [citado 2004 Jul 09]; 20(11): 10-15. Disponível em: http://periodicos.uem.br/ojs/index.php/ ActaSciHealthSci/article/view/1606,2015.

12. Lessa R, Rosa A, Vasconcellos H. Enfermagem e Acolhimento: A importância da interação dialógica no pré-natal. Rev. pesq.: cuid. fundam. online [Internet]; 2017 [citado 2010 Jul/set 12]; 2(3): 1105-1110. Disponível em: http://dialnet.unirioja.es/descarga/articulo/3651897.pdf

13. Rafael E, Silva R, Rodrigues M. 0 significado da amamentação para a mulher primípara. Enferm [Internet]; 2017 [citado 2005 ago 09]; (2): 221 - 8. Disponivel em: http://www.scielo.br/pdf/ress/v25n3/2237-9622ress-25-03.pdf.

14. Crivellaro I. fonoaudióloga e Consultora internacional em Amamentação pelo IBLCE, sobre ordenha de leite materno. [Internet]; 2017 [citado 2005 maio 07]; 9 (2): 221 - 8 Disponível em: http://tetenossodecadadia. com.br/sobre-ordenha-de-leite-materno-7-coisas-que-voce-precisa-saber 15. Mcewen $M$, Wills $E$ M. Bases teóricas de enfermagem. 4. ed. Porto Alegre: Artmed; 2015.

16. Organização das Nações Unidas (BR). Amamentação diz OPAS/ OMS. Notícias do Brasil [Internet]; 2018 [acesso em 08 jun 2018]; Disponivel em: https://www.paho.org/bra/index.php?option=com_content \& view=article \& id=5631:oms-e-unicef-lancam-novas-orientacoes-para-promover-aleitamento-materno-em-unidades-de-saude-de-todo-o-mundo \& Itemid $=820$

17. Clínicas da Família +50 da cidade do Rio de Janeiro. Clínica da Família Olímpia Esteves, Rio de Janeiro: PCRJ; p. 19-22; 2012.

18. Brasil, Ministério da Saúde, Ministério da Educação, Secretaria de Atenção à Saúde, Departamento de Ações Programáticas Estratégicas, Área Técnica de Saúde da Mulher, Pré-natal e Puerpério: atenção qualificada e humanizada. Série A. Normas e Manuais Técnicos $n^{\circ} 5$. Brasília (DF); 2015.

19. Brasil, Ministério da Saúde, Secretaria de Atenção à Saúde. A estratégia de apoio à mulher trabalhadora que amamenta. [Internet]; 2017 [acesso em 20 maio 2017]. Disponível em: 19. http://portalsaude.saude. gov.br/index.php/oministerio/principal/secretarias/515-sas-raiz/dapes/ saude-da-crianca-e-aleitamento-materno/l3-saude-da-crianca-e- aleitamento-materno/12878-mulher-trabalhadora-que-amamenta. 